which is not a race as such, though any doctor of any age can "compete" against a reasonable age-related target time. This annual event was initiated in 1970 by Professor Peltokallio and last year 338 doctors participated.

A similar event has been arranged for Sunday 24 September 1978, to be held in Leeds. This has been organised in association with the Leisure Services Department of the Leeds City Council and the Carnegie School of Physical Education.

There has been encouragement of exercise by the Royal College of Physicians and it is hoped that the early notice of this event will provide a spur for many doctors to undertake regular physical activity during the summer months. Further details will be provided within the next few weeks but any interested doctor may write to me.

I D ADAMS

St James's Hospital,

SIR,- Two running events for doctors will be held on 7 October 1978 at Meadowbank Stadium, Edinburgh. The events are 10000 metres for men and 3000 metres or 5000 metres for women. Any registered medical practitioner will be eligible to take part.

The events will be held under the auspices of the Meadowbank Sports Medicine Centre. They will not be races in the usual sense of the word in that there will be no prizes, but each competitor will be timed and will receive a certificate stating the distance he has covered and the time taken. The aim is that each runner should run at his own speed to establish his own standard. An entry fee will be made to cover the cost of staging the programme.

There is growing awareness of the value of endurance forms of exercise in the promotion of physical health and when it is seen that doctors are practising what they preach the effect on the general public can only be beneficial. Events like those stated are held annually in Finland, as reported by $\mathrm{Dr} T$ Kosonen (Personal View, 21 January, p 169). This article provided the inspiration for the proposed events in Edinburgh.

Any doctor who wishes to take part should write for further details and an entry form to me, enclosing a stamped addressed envelope.

Should there be insufficient support the events will be cancelled.

Northern General Hospital,

Edinburgh EH5 2DQ

\section{New consultant contract}

SIR,-In the north-west consultants' opinion has changed since the contract negotiations began and they want to reject the new contract. We appreciate the efforts of David Bolt, but gratitude must not obscure impartial and detached evaluation of the proposals. The new contract has been negotiated by a working party, and as a member of the Central Committee for Hospital Medical Services' Negotiating Subcommittee I have been kept informed of the progress and have been able to comment. In October 1977 the Department of Health circulated a confidential draft contract to regional and area health authorities on a "need to know" basis, and one medical executive committee chairman circulated it to all consultants in his area. At the request of the North-western Regional Committee for Hos- pital Medical Services it was sent to all members and discussed. The north-west is against the new contract and wants an open contract, properly priced. At the meeting of the CCHMS on 4 May I proposed an amendment: "This committee recommends that the new contract be accepted in principle and without prejudice in order that pricing may be obtained." The representatives from the northwest withdrew this proposal because the chairman of the Negotiating Subcommittee felt that the time had come to stop trying to paper over the cracks. Instead, they voted against the main proposal (13 May, p 1298).

As a member of the Negotiating Subcommittee it is my primary objective to obtain better conditions for consultants. I am not convinced that the new contract will do this In 1948 the $27 \frac{1}{2}$-hour session contract was good one. It was succeeded by the less advantageous nine-session contract and then by the iniquitous maximum part-time contract. The new contract is a worthy successor in this downhill progression. The maximum part-time contract was phrased "substantially whole time" to encompass a consultant's continuing responsibility for patients under his care. The new contract states: "The number of additional notional half-days contracted for on a regular basis may not exceed five in the case of consultant who undertakes not to engage in private practice or three in the case of a consultant not giving such an undertaking." There would have been no problem if this had read: "The employing authority must be satisfied that a consultant's other commitments are such that he can give sufficient time for the discharge of additional NHS duties." The employing authority would then be free to consider golf, private practice, and other timeconsuming activities. Isolation of one activity, private practice, is illiberal. The freedom of general practitioners and junior staff is not so restricted. I see its imposition on consultants as unacceptable. Once upon a time it was unacceptable to them. In December 1977 the CCHMS resolved: "That the CCHMS instructs its Negotiating Subcommittee to stand firm in its negotiations with the Secretary of State on the new consultant contract; in particular there must be no compromise on the twin principles of: (1) a consultant's right to spend his non-contractual time as he sees fit (like any other citizen of the United Kingdom); (2) payment should be for work done rather than for work not done." Freedom is at stake. The issue is too great for it to be ignored or shirked and many people outside medicine will look to consultants for leadership.

Other issues, though less important, are weighty enough for the contract to be rejected.

(1) A notional half day is devalued to $3 \frac{1}{2}$ hours from $3 \frac{1}{2}$ hours less travelling time of up to one hour. How many extra sessions, allocated for travelling time, are required to compensate for a $28 \%$ devaluation? The addition of one hour to each of 9 old NHDs is worth just over $2 \frac{1}{2}$ new NHDs per week. Such elementary arithmetic will not escape the Review Body's scrutiny. The NHD is further extended and devalued by the agreement on recall fees, which are not payable between 8.30 am and $7 \mathrm{pm}$. This period of $10 \frac{1}{2}$ hours is the length of 3 new NHDs and it applies from Monday to Friday, covering a total time equivalent to 15 NHDs.

(2) The merit award system should not be allowed to confuse the issues in a new contract. Its reformation should apply to old and new contracts and be discussed outside the new contract proposals

(3) Emergency recall fees are, like domiciliary visits, an item-of-service payment which may compensate for additional work load, but these recall fees are not unconditionally on offer to holders of the old contract. Older consultants should beware of voting for the new contract so that they may obtain an advantage for the old contract which they intend to retain.

(4) Superannuation benefits are difficult to evaluate and dynamisation may be beneficial to younger consultants but is probably disadvantageous to a consultant close to retirement.

(5) I have seen the skilful DHSS negotiators in action on the Joint Negotiating Committee. Much as they would like to help, they are bound by the regulations as written, not by the interpretation which the profession would like to choose. The new contract is a morass of uncertainties and obscurities. Two years after the introduction of the new junior hospital doctors' contract interpretation is far from complete. In the early days major differences of opinion were resolved by industrial action. What hope is there that differences of interpretation in a future consultant contract will be resolved to the advantage of consultants ?

(6) The chairman of the CCHMS has stated that a further ballot after pricing might not be required. How much better it would have been if an unconditional promise had been made to hold a ballot at that time. Then at least consultants would know how much they were going to be paid for giving up their freedom.

What would be the alternative to the present proposals ? Many of the principles conceded by the Secretary of State in the new contract offer make a good foundation on which an acceptable consultant contract could be built. The present offer should be rejected and David Bolt asked to go back and try again. The Review Body report is welcome for its steps towards restoring the position of consultants. It makes clear, however, that money should be redistributed but not added in a new contract and it restores differentials by curtailing financial advantages of the new junior contract. The possibility of asking the Review Body to price the NHD as a separate and clearly defined entity should be pursued as resolved by CCHMS on 9 February 1978. Those parts of the present offer which relate to the old contract should be consolidated now. I urge consultants not to listen to those who say that additional sessions are not obtainable under the old contract. They were offered in writing by Mrs Barbara Castle in April 1975 (26 April 1975, p 203). Would the present Secretary of State be prepared to go back on a written undertaking of his predecessor in the same way as he was prepared to go back on a verbal offer made by his negotiators? I believe that refusing the new contract offer will do more for consultants than accepting it. Some may accept from fear of worsening and restrictive pay policy; from faith in the Government's benevolence; from hope of better things to come; or from charity towards political idealism. Some members of the CCHMS have lost their way and have discarded a principle in order that they may grasp an illusion because of political expediency or economic necessity. The achievement of a new contract must remain secondary to the prime objective, which is to retain freedom and obtain better conditions for consultants. This is the only way in which patients' interests can be safeguarded.

I would like to thank my colleagues on the Negotiating Subcommittee and the CCHMS who have sharpened my argument. I respect their opinions though I do not agree with all of them all the time.

JOHN S S STEWART North-western Regional Committee
for Hospital Medical Services

Wigan, Lancs

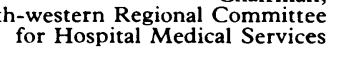

